REVIEW

\title{
Application of Kingdon and Hall Models to Review Environmental Sanitation and Health Promotion Policy in Ethiopia: A Professional Perspective as a Review
}

\author{
Feleke Doyore Agide ${ }^{1,2}$, Gholamreza Garmaroudi ${ }^{*}$, Roya Sadeghi ${ }^{3}$, Elham \\ Shakibazadeh $^{3}$, Mehdi Yaseri ${ }^{4}$, Zewdie Birhanu Koricha ${ }^{5}$, Tadesse Bekele \\ Tefese $^{6}$
}

\author{
OPEN ACCESS \\ Citation: Feleke Doyore Agide, \\ Gholamreza Garmaroudi, Roya Sadeghi, \\ Elham Shakibazadeh, Mehdi Yaseri, \\ Zewdie Birhanu Koricha, Tadesse Bekele \\ Tefese. Application of Kingdon and Hall \\ Models to Review Environmental \\ Sanitation and Health Promotion Policy in \\ Ethiopia: A Professional Perspective as a \\ Review. Ethiop J Health Sci. \\ 2018;29(2):277. \\ doi:http://dx.doi.org/10.4314/ ejhs.v29i2.15 \\ Received: August 01, 2018 \\ Accepted: September 24, 2018 \\ Published: March 1, 2019 \\ Copyright: (C) 2019 Feleke Doyore Agide, \\ et al. This is an open access article \\ distributed under the terms of the Creative \\ Commons Attribution License, which \\ permits unrestricted use, distribution, and \\ reproduction in any medium, provided the \\ original author and source are credited. \\ Funding: Nil \\ Competing Interests: The authors declare \\ that this manuscript was approved by all \\ authors in its form and that no competing \\ interest exists. \\ Affiliation and Correspondence: \\ ${ }^{1}$ Department of Health Education and \\ Promotion, Tehran University of Medical \\ Sciences, Tehran, Iran \\ ${ }^{2}$ Department of Public Health, Wachemo \\ University, Hossana, Ethiopia \\ ${ }^{3}$ Department of Health Education and \\ Promotion, Tehran University of Medical \\ sciences, Tehran, Iran \\ ${ }^{4}$ Department of Epidemiology and \\ Biostatistics, Tehran University of \\ Medical Sciences, Tehran, Iran \\ ${ }^{5}$ Department of Health, Behavior and \\ Society, Jimma University, Ethiopia \\ ${ }^{6}$ Department of Medicinal Chemistry, \\ Faculty of Pharmacy, Tehran University \\ of Medical Sciences, Tehran, Iran \\ *Email: garmaroudi@tums.ac.ir
}

\begin{abstract}
BACKGROUND: In the world, many countries, including Ethiopia, are framing policies to roll back the problem of the sanitation. For this, the Kingdon and Hall models are the two distinct models formed to articulate the policy agenda to the health problem. The Kingdon model includes problem, policy and politics streams whereas the Hall model includes legitimacy, feasibility and support of the health policies. Therefore, this review aims to integrate the two models with diseases prevention and health promotion policies of Ethiopia.

METHODS: We used the existing frameworks of the models as a guiding principle. Then, we applied the frameworks of the two models as an important consideration to interlink policy agenda to a given health problem. We also described the existing scientific literature about the sanitation and health promotion. After thoroughly reviewing, possible policy inputs and country setups were included with a brief discussion by comparing different kinds of literatures.

RESULTS: The two models are recognized as an opportunity to get an essential sanitation policy. The government settled and has closed links to the new innovation as an emerged discourse. Therefore, the two model streams came together for setting sanitation problem on the policy agenda. The technical feasibility, public acceptability and congruence with existing values were all judged to be favorable.

CONCLUSION: The integration of policies within the policy frameworks has very important outputs in various countries. Therefore, the field specialists should figure out the problem of policy integration through policy evaluation researches.
\end{abstract}

KEYWORDS: Models, Sanitation, Health Promotion, Policy
INTRODUCTION
Global burden of environmental sanitation problem is enormous. According to WHO, 2.6 billion people are suffering from environmental

DOI: http://dx.doi.org/10.4314/ejhs.v29i2.15 
sanitation and lack of adequate water supply (1). The sanitation problems constitute $10 \%$ of global burden of diseases. However, improving sanitation is known to have a significant beneficial impact on health both in households and across communities (1-3). In Ethiopia, environmental sanitation includes the conditions like safe and adequate water, clean and safe ambient air, safe animal and human waste disposal, protection of food from contaminants, and adequate housing in clean and safe surroundings $(4,5)$.

In Ethiopia, over 27 million people still do not have access to any form of toilet. The sanitation coverage at the household level is estimated to be at $63 \%$ where as in rural Ethiopia, $43 \%$ of people were defecating in the open field as compared to $8 \%$ in urban areas $(6,7,8,9)$.

The lack of access to improved sanitation and the practice of open defecation have a significant socio-economic impact on the households and the whole communities $(1,9)$. While it is clear that access to latrines in Ethiopia is still low, trends show a slow increase in those people adopting fixed place defecation (10).

In Ethiopia, in response to environmental sanitation, environmental health activities maintained from 1950 during the 'basic health service provision' and extended their view to primary health care in 1970's and to the current health sector development programs $(11,12,13)$. Despite massive resources and intensified intervention on environmental sanitation, the desired decline on achieving the WHO target is not yet achieved. Therefore, this review was conducted to integrate the two models with diseases prevention and health promotion policies of Ethiopia.

\section{METHODS}

We used the existing frameworks of the models as a guiding principle. Then, we applied the frameworks of the two models as an important consideration to interlink policy agenda to describe and state the existing knowledge about the sanitation through health promotion. For this, the Hall and Kingdon models are the two distinct models formed to articulate the policy agenda in the given situation or health problem. The Kingdon model includes problem, policy and politics streams whereas the Hall model includes legitimacy, feasibility and support of the given health policies (14). Problem, in a kingdon model, is conceived as the problem related to sanitation as a result of sanitation and health promotion policies. Policy, in a kingdon model, is defined as a health promotion policy to curb sanitation problems. Politics is conceived as the political dimensions where a government is diffusing the health promotion action concerning sanitation. Legitimacy means the legality of the implementation of health promotion actions at community level. Feasibility is the ability of the community to curb the sanitation problem owing to socio-economic conditions. Support is action of the communities to decrease sanitation problem or to do health promoting actions identified by the government and stakeholders. After thoroughly reviewing, possible policy inputs and country setups were included with a brief discussion by comparing different kinds of literatures.

\section{RESULTS}

\section{Kingdon model: A problem stream}

Sanitation related diseases: Poor environmental sanitation or lack of environmental hygiene leads to various diseases like diarrheal diseases $(1,5)$. This was confirmed by an author called Chadwick in 1842 on his seminal report on an inquiry into the sanitary condition of the laboring population of Great Britain (15). The issue of environmental sanitation starts at that time was linking the problem with diseases (5). In this regard, at any point in time, half of African populations face the problems associated with poor sanitation and hygiene (16). In the Ethiopian context, these diseases are known by poverty and lack of awareness (17). Given all the situation at hand, Ethiopian burden of diseases increased its climax by marking diarrheal diseases as ten top diseases (18).

Diarrheal diseases are the first top diseases in Ethiopia causing death in millions particularly under 5 (18). In 2016, for example, diarrhea was 
the leading cause of death among children under 5 in Ethiopia resulting in $10 \%$ of all deaths (13). Various cross-sectional studies indicated that improved sanitation can reduce rates of diarrheal diseases (19-22). A longitudinal cohort study in Salvador, Brazil, found that an increase in sewerage coverage from $26 \%$ to $80 \%$ of the target population resulted in a $22 \%$ reduction of diarrheal prevalence in children under 3 years of age (23). Similarly, a recent meta-analysis that explored the impact of the provision of sewerage on diarrhea prevalence reported a pooled estimate of a $30 \%$ reduction in diarrhea prevalence and up to $60 \%$ reduction in areas with especially poor baseline sanitation conditions (24). The study concluded that diarrheal disease rates could be substantially decreased by interventions designed to improve the environmental sanitation (23).

Trachoma is an eye infection spread mainly through poor hygiene caused unsafe environmental sanitation conditions. About 6 million people are blind today because of trachoma (25). It affects women two to three times more than men. Children are also especially susceptible (26).

Fluorosis is a disease caused by high concentration of fluoride mineral occurring and in turn results in bone diseases (27). At least twenty five countries across the globe are suffering from its endemic nature. Though the total number of people affected is not known, a conservative estimate would number in the tens of millions (28). Guinea worm disease is transmitted by people-topeople contact when drinking water contaminated with Dracunculus larvae. This sanitation and water related disease causes debilitating ulcers. The incidence of cases of Guinea worm disease is steadily decreasing worldwide as a result of a concerted international initiative (4). However, in 2002, there were still 50,000 cases reported in a total of 13 countries in Africa, including Ethiopia $(4,29)$.

Typhoid fever is caused by lack of food sanitation (21,30). About 22 million people are affected by typhoid every year (31). Schistosomiasis is a disease caused by parasitic worms and are related to unsanitary conditions (also known as bilharzia) (30). They can damage the liver, intestines, lungs and bladder. About 200 million people are infected with schistosomiasis,
20 million of whom suffer severe consequences. Studies have found that adequate water supply and sanitation which reduces contact with contaminated surface water could reduce infection rates by 77 per cent (30).

A clean environment and adequate sanitation are vital factors in averting opportunistic infections associated with HIV/AIDS, and in the quality of life of people living with the disease $(32,33)$. AIDS-affected people are more susceptible to unsanitary conditions than healthy individuals (34). Continuing a healthy environment is essential to safeguarding the health, quality of life and productivity of people living with HIV/AIDS $(32,33)$. Intestinal worms are caused by intestinal parasitic worms (also known as helminthes) through contact with unsanitary conditions particularly soil that has been contaminated with human feces from an infected person (35). Intestinal worms infect about 10 per cent of the population in the developing world, including Ethiopia (36). About 400 million school-age children are infected by roundworm, whipworm and/or hookworm $(35,36)$. In fact, roundworm and whipworm alone are estimated to affect onequarter of the world's population (36).

Malaria is a serious disease caused by a parasite carried by certain types of mosquitoes. Humans are infected when bitten by the mosquitoes (37). Each year, there are 300 million to 500 million cases of malaria throughout the world and about 1 million child deaths $(38,39)$. Reducing the mosquito population in households by eliminating standing water (caused by poor drainage and uncovered water tanks) can be an important factor in reducing malaria cases (37-39). Kingdon model: Policy and politics streams Deploying health extension workers and their roles: The Ethiopian Federal Ministry of Health (FMOH) has made major strides over the last 15 years $(40,41)$, investing heavily in building the country's health infrastructure and deploying health extension workers in each kebele. In addition to that, training and deploying community health agents and community development army as another part of the previous years achievement of the FMOH $(41,42)$.

The FMOH introduced health extension program for disease prevention and health 
promotion through developing the packages for each diseases to reach the people at the grassroots (kebeles) $(43,44)$. The aim was to make the rural poor to the universal access to health care services and decentralizing the services at that level $(43,45)$. The health extension program has got 16 and 15 packages for rural and urban areas respectively. Sanitation and hygiene is a major problem in both areas $(45,46)$. The initiative accomplishers are named as health extension workers (44).

\section{Community health agents/community} development armies: Community health agents/community development armies are responsible to change the community behavior and attitude towards sanitation and hygiene through communal activities. The approach has proved effective and cost-effective in various parts of the country (46). The community health agents have frequent contact with community and health extension workers. That is why they are called bridge health workers and flagships supporter. They are sometimes called the people to speak for community at grassroot level $(46,47)$.

Community lead Total sanitation: Community health workers, apart from health extension workers, have a significant role in changing the behavior of the community through mass mobilization to be a model $(40,47)$. These motivated families usually are known as model families who applied the given health extension packages. The main aim of community-led total sanitation (CLTS) is to make communities at large to be free from "open field defecation" (and hence for toilets) through mass communications-based approach $(40,48)$. CLTS was applied in Ethiopia through mass mobilization and developing health learning materials and posting them in public areas $(40,48)$. Model families and other socioeconomically advantaged groups are used to raise and ignite the community awareness on open field defecation as an important contaminant of the environment and food ingested by householders (49). In the Ethiopian setup, communal pit ventilated latrines are used as an approach to end the open field defecation and to have clean and healthy environment $(49,50)$. This has shown tremendous potential in increasing awareness and practice of using latrines because of Ethiopian flagships of health extension workers. The degree of acceptability of CLTS depends on the way the community acquired information and cultural suitability and acceptance (49).

Sanitation marketing: This concept is derived from social marketing that states the use of marketing theory and skills with the fulfillment of the requirements like products, place, promotion, and price plus the added variable policy makes the community to be aware of a given health problem $(2,51)$. Thus, sanitation marketing is a means to raise the awareness of the individuals, groups, and communities to achieve quality of life $(52,53)$. Integration of health promotion interventions and diseases prevention strategies at community and stakeholders levels about the use of sanitation packages is verily a question of all $(2,52)$. Indeed, having an idea about the community felt need is used to know the practical intervention demand and supply of product, promotion, place, price and policy as contextualized in social marketing framework $(52,53)$.

Health promotion as a response: Health promotion plays several roles to ensure improvements in water, sanitation and hygiene (54). This thus ensures the promotion of hygiene at household and community levels including environmental and personal hygiene (55). These measures promote environmental, animal and human health thus contributing to one Health (56). After Al-Mata meeting in Kazakhstan, mid-1980, WHO initiated the health promotion program considered as an essential strategy in achieving the goal "Health for all" (57). Health promotion got five pillars to promote every health aspect including environmental hygiene in Ottawa charter 1985 (58). Ethiopia also adopted these pillars though it failed to fully apply them as intended because of resource constraints $(58,59)$.

Health promotion particularly sanitation promotion focuses on prevention strategies to reduce the risk of developing diseases and other morbidities (59). Health promotion and disease prevention programs often address social determinants of health, which influence modifiable behaviors (60). 
Health promotion strategies in Ethiopia are verily interlinked with various methods of delivering health information and streamlining of policies with diseases conditions. The drastic shift from basic services to health sector development program in Ethiopia has a significant contribution in reducing the morbidity and mortality of sanitation-related behavioral diseases $(61,62)$. In general, health promotion is applied through deploying health extension workers, community health agents, community development army and community lead total sanitation particularly the approach of free of open field defecation (2 63).

\section{Hall Model: Legitimacy, feasibility and support wings}

The Hall model argues that a policy issue only comes on the policy agenda when an issue and the possible solution are high in terms of their legitimacy, feasibility and support. Feasibility refers to the implementation process of a policy (64). The avoidance of the centralized health services and the replacement of the decentralization need the new policy (45). Following that, the FMOH has endorsed the policy of decentralization by changing from six-tier system to three-tier system through legitimacy (48). The application of the legitimacy rule at country level was expanding the service providing the institution to lowest grassroot level (kebele) $(8,45,64)$. This was achieved through developing and constructing health centers and health posts at kebele level, and deploying health extension workers as family health workers to work intimately with the community $(42,45)$.

Health professionals and managers are the concerned authorities to convince the community and other stakeholders $(42,62)$. It was expected that there might be difficulty in getting support. Support was more difficult because there was a considerable drought resulted from poverty and famine (21). The socio-economic and awareness level of the society is very low at country level in general and rural parts in particular. According to the country's belief, the communities are the change agents and the solutions (42). In addition, the Ministry of Health $(\mathrm{MOH})$, as a facilitating agent, was able to mobilize the community at large to have a clean environment and good sanitary conditions $(42,53)$.

\section{DISCUSSION}

This review gives insight for the country's sanitation and health promotion policies. In recent years, sanitation and health promotion systems are being challenged by social, economic, political and environmental disorders throughout the country $(1,13)$. At the country level, government budgets for health affairs are larger than ever, and healthcare costs have grown much faster than other sectors. However, the lack of national policies was a major constraint to curb sanitation problems in previous years $(64,65)$. This is similar with the case in Bangladesh (66).

Mainstreaming sanitation problems in different governmental and non-governmental organizations is still an unfinished agenda despite the existence of its nomenclature and framework $(4,67)$. To talk frankly, political streams of governments cannot play their key roles as watchdogs of sanitation problems (67). Another longitudinal study in urban Brazil found that the major risk factors for diarrhea in the first three years of life were poor sanitation conditions, the presence of intestinal parasites and absence of prenatal examination $(23,68)$.

The dramatic change should be a bottom-up approach to make the concerned organization to create sanitation lead institutions. The idea has been mostly advanced in Europe after health in all policies idea is endorsed (69). Community health workers enhance the awareness of individuals, groups and the community by focusing on household behaviors and the whole community. Environmental sanitation is a multifaceted issue that includes social, political, economic and environmental development (69).

Policy and political streams play a pivotal role to put a clear job description with responsibility and authority. Framing a legitimate rule and putting the law in a country's constitution enables people to have a good idea in the sanitation issues. In Ethiopia, a political leadership is integrated with amicable policy and specific budget lines for sanitation $(46,59)$.

Community support is a very important component to value their health and to recognize

DOI: http://dx.doi.org/10.4314/ejhs.v29i2.15 
their potential. Meanwhile, the support for sanitation was made by building pit latrines and pit ventilated latrines with existing resources. Developing the skills of the community to manage environmental sanitation is left as an assignment for health extension workers (2). This idea is similar with developed countries family nurses and doctors (70). As an alternative, the transition centralized supply-led infrastructure provision to decentralize and people-centered demand creation is an essential pillar to meet that demand. This way helps bottom-up approaches to be successful in transforming sanitation from a minor level to a major area of countries' developments. The other strategy is fully applying the endorsement of health in all policies for the sanitation case too. A Primary Health Care Unit (PHCU) has a powerful motivation for improving sanitation and much strength to contribute to achieving health for all goals $(2,71)$. This is similar with Makoni and Tsholotsho Districts of Zimbabwe (71,72). When we compared to literature from Asian countries, one recent study estimates that only $39 \%$ of ignited villages achieved open defecation-free status (73). Finally, besides the financial constraint to improve sanitation condition in Ethiopia, there are knowledge gaps regarding effective use of services, social marketing and micro-credit of revolving fund for financing sanitation facilities. As field experts, we believe that applying all the basic principles of health promotion is the most important thing in sanitation promotion and behavior modification. Therefore, we recommend that field specialists figure out the problem of not using the existing models as a framework and also not integrating policy models for policy evaluation researches.

\section{ACKNOWLEDGEMENTS}

The authors would like to thank all the staff members of health education and promotion in Tehran University of Medical Sciences. Acknowledgement is also extended to our friends who encouraged us to write this manuscript.

\section{REFERENCES}

1. UNICEF. WHO (2010) Progress on Sanitation and Drinking Water-2010 update. World Health Organization and UNICEF, France.40.

2. Mara D, Lane J, Scott B, Trouba D. Sanitation and health. PLoS medicine. 2010;7(11):e1000363.

3. Harris M, Alzua ML, Osbert N, Pickering AJ. Community-level sanitation coverage is more strongly associated with child growth and household drinking water quality than access to a private toilet in rural Mali. Environmental Science \& Technology. 2017.

4. WHO. Progress on sanitation and drinking water: 2015 update and MDG assessment: World Health Organization; 2015.

5. Prüss-Ustün A, Bartram J, Clasen T, Colford JM, Cumming O, Curtis V, et al. Burden of disease from inadequate water, sanitation and hygiene in low-and middle-income settings: a retrospective analysis of data from 145 countries. Tropical Medicine \& International Health. 2014;19(8):894-905.

6. Pasteur K. Keeping Track: CLTS Monitoring, Certification and Verification. 2017.

7. Beyene A, Hailu T, Faris K, Kloos H. Current state and trends of access to sanitation in Ethiopia and the need to revise indicators to monitor progress in the Post-2015 era. BMC public health. 2015;15(1):451.

8. Butterworth J, Welle K, Bostoen K, Schaefer F. WASH sector monitoring. Achieving water security: Lessons from research in water supply, sanitation and hygiene in Ethiopia. 2013:49-67.

9. Butterworth J, Welle K, Bostoen K, Chaka T, Goshu A, editors. Monitoring WASH in Ethiopia: messages from a sector symposium. RiPPLE Meeting Report; 2010.

10. Yimam YT, Gelaye KA, Chercos DH. Latrine utilization and associated factors among people living in rural areas of Denbia district, Northwest Ethiopia, 2013, a cross-sectional

DOI: http://dx.doi.org/10.4314/ejhs.v29i2.15 
study. The Pan African medical journal. 2014;18.

11. Kloos H. Primary health care in Ethiopia under three political systems: Community participation in a war-torn society. Social Science \& Medicine. 1998;46(4-5):505-22.

12. Kumie A, Ali A. An overview of environmental health status in Ethiopia with particular emphasis to its organization drinking water and sanitation: a literature survey. Ethiopian Journal of Health Development. 2005;19(2):89-103.

13. PAHO. Health, environment and sustainable development: towards the future we want. A collection of texts based on the PAHO Seminar Series 'Towards Rio+ 20'that occurred in the period between 8 February and 13 June 2012. PAHO Washington; 2013.

14. Bache I. Measuring Quality of Life-An Idea Whose Time Has Come? Agenda-Setting Dynamics in Britain and the European Union. Well-being in contemporary society: Springer; 2015. p. 197-214.

15. Chadwick E. Report to Her Majesty's Principal Secretary of State for the Home Department from the Poor Law Commissioners on an Inquiry Into the Sanitary Condition of the Labouring Population of Great Britain, with Appendices: HM Stationery Office; 1842.

16. Satterthwaite D. The key issues and the works included. The Earthscan Reader in Sustainable Cities, Earthscan, London, pp321. 1999.

17. Calow RC, Ludi E, Tucker J. Achieving water security: Lessons from research in water supply, sanitation and hygiene in Ethiopia: Practical Action Publishing; 2013.

18. Grimes JE, Tadesse G, Mekete K, Wuletaw Y, Gebretsadik A, French MD, et al. School water, sanitation, and hygiene, soiltransmitted helminths, and schistosomes: national mapping in Ethiopia. PLoS neglected tropical diseases. 2016;10(3): e0004515.

19. Adane M, Mengistie B, Kloos H, Medhin G, Mulat W. Sanitation facilities, hygienic conditions, and prevalence of acute diarrhea among under-five children in slums of Addis Ababa, Ethiopia: Baseline survey of a longitudinal study. PloS one. 2017;12(8): $\mathrm{e} 0182783$.

20. Diène AN, Schindler C, Cissé G, Sy I, Utzinger J, Ndione JA, et al. Prevalence of diarrhoea and risk factors among children under five years old in Mbour, Senegal: a cross-sectional study. Infectious diseases of poverty. 2017;6(1):109.

21. Mohammed S, Tamiru D. The burden of diarrheal diseases among children under five years of age in Arba Minch District, Southern Ethiopia, and associated risk factors: a crosssectional study. International scholarly research notices. 2014;2014.

22. Waddington H, Snilstveit B. Effectiveness and sustainability of water, sanitation, and hygiene interventions in combating diarrhoea. Journal of development effectiveness. 2009;1(3):295-335.

23. Barreto ML, Genser B, Strina A, Assis AMO, Rego RF, Teles CA, et al. Effect of city-wide sanitation programme on reduction in rate of childhood diarrhoea in northeast Brazil: assessment by two cohort studies. The Lancet. 2007;370(9599):1622-8.

24. Norman G, Pedley S, Takkouche B. Effects of sewerage on diarrhoea and enteric infections: a systematic review and metaanalysis. The Lancet infectious diseases. 2010;10(8):536-44.

25. Burton MJ, Mabey DC. The global burden of trachoma: a review. PLoS neglected tropical diseases. 2009;3(10): 460.

26. Asres M, Endeshaw M, Yeshambaw M. Prevalence and Risk Factors of Active Trachoma among Children in Gondar Zuria District North Gondar, Ethiopia. Journal of Preventive Medicine. 2016.

27. Wondwossen F, Åstrøm AN, Bårdsen A, Bjorvatn K. Perception of dental fluorosis amongst Ethiopian children and their mothers. Acta Odontologica Scandinavica. 2003;61(2):81-6.

28. Kloos H, Haimanot RT. Distribution of fluoride and fluorosis in Ethiopia and prospects for control. Tropical Medicine \& International Health. 1999;4(5):355-64.

29. Beyene HB, Bekele A, Shifara A, Ebstie YA, Desalegn Z, Kebede Z, et al. Elimination of

DOI: http://dx.doi.org/10.4314/ejhs.v29i2.15 
Guinea Worm Disease in Ethiopia; Current Status of the Disease's, Eradication Strategies and Challenges to the End Game. Ethiopian medical journal. 2017;55(Suppl 1):15.

30. Farley J. Bilharzia: a history of imperial tropical medicine: Cambridge University Press; 2003.

31. Crump JA, Luby SP, Mintz ED. The global burden of typhoid fever. Bulletin of the World Health Organization. 2004;82(5):346-53.

32. Dept WHOSA. Global status report: alcohol policy: World Health Organization; 2004.

33. Shiffman J. HIV/AIDS and the rest of the global health agenda. Bulletin of the World Health Organization. 2006;84(12):923-.

34. Oramasionwu CU, Daniels KR, Labreche MJ, Frei CR. The environmental and social influences of HIV/AIDS in sub-Saharan Africa: a focus on rural communities. International journal of environmental research and public health. 2011;8(7):296779.

35. Pruss-Ustun A, WHO. Safer water, better health: costs, benefits and sustainability of interventions to protect and promote health. Bulletin of the World Health Organization. 2008.

36. Nguyen NL, Gelaye B, Aboset N, Kumie A, Williams MA, Berhane Y. Intestinal parasitic infection and nutritional status among school children in Angolela, Ethiopia. Journal of preventive medicine and hygiene. 2012;53(3):157.

37. Alemu A, Abebe G, Golassa L, Tsegaye W. Urban malaria and associated risk factors in Jimma town, south-west Ethiopia. Malaria Journal. 2011;10(1):173.

38. Ayele DG, Mwambi HG, Zewotir TT. Prevalence and risk factors of malaria in Ethiopia. Malaria Journal. 2012;11(1):195.

39. Tadesse F, Fogarty AW, Deressa W. Prevalence and associated risk factors of malaria among adults in East Shewa Zone of Oromia Regional State, Ethiopia: a crosssectional study. BMC public health. 2018;18(1):25.
40. Tessema RA. Assessment of the implementation of community-led total sanitation, hygiene, and associated factors in Diretiyara district, Eastern Ethiopia. PloS one. 2017;12(4): $\mathrm{e} 0175233$.

41. Behailu S, Redaie G, Mamo D, Dimtse D, Newborne P. Promoting Sanitation and Hygiene to rural households in SNNPR, Ethiopia. 2010.

42. Mangham-Jefferies L, Mathewos B, Russell J, Bekele A. How do health extension workers in Ethiopia allocate their time? Human resources for health. 2014;12(1):61.

43. Hailu G, Abajobir A. Assessment of Functionality of Health Extension Workers and Its Determinants in East Gojam, Northwest Ethiopia: A Comparative CrossSectional Study. Primary Health Care. 2015;4(175):2167-1079.1000175.

44. Sebhatu A. The implementation of Ethiopia's Health Extension Program: an overview. Addis Ababa, Ethiopia. 2008.

45. Banteyerga H. Ethiopia's health extension program: improving health through community involvement. MEDICC review. 2011;13(3):46-9.

46. Yitayal M, Berhane Y, Worku A, Kebede Y. The community-based Health extension Program significantly improved contraceptive utilization in West gojjam Zone, ethiopia. Journal of multidisciplinary healthcare. 2014;7:201.

47. Daniel EE, Masilamani R, Rahman M. The effect of community-based reproductive health communication interventions on contraceptive use among young married couples in Bihar, India. International family planning perspectives. 2008:189-97.

48. Crocker J, Saywell D, Bartram J. Sustainability of community-led total sanitation outcomes: Evidence from Ethiopia and Ghana. International Journal of Hygiene and Environmental Health. 2017;220(3):5517.

49. Crocker J, Geremew A, Atalie F, Yetie M, Bartram J. Teachers and sanitation promotion: an assessment of community-led

DOI: http://dx.doi.org/10.4314/ejhs.v29i2.15 
total sanitation in Ethiopia. Environmental Science \& Technology. 2016;50(12):6517-25.

50. Garn JV, Sclar GD, Freeman MC, Penakalapati G, Alexander KT, Brooks P, et al. The impact of sanitation interventions on latrine coverage and latrine use: A systematic review and meta-analysis. International Journal of Hygiene and Environmental Health. 2016.

51. Indonesia N. Total Sanitation and Sanitation Marketing Research Report. Water and Sanitation Program, World Bank: Washington $D C ; 2009$.

52. Jenkins MW, Scott B. Behavioral indicators of household decision-making and demand for sanitation and potential gains from social marketing in Ghana. Social Science \& Medicine. 2007;64(12):2427-42.

53. Mukherjee N. Total Sanitation and sanitation marketing project: Indonesia country update. WSP, Washington, DC. 2009.

54. Wicken J. Beyond construction: Use by allAn overview of a South Asian sanitation and hygiene practitioners' workshop. Construction. 2008.

55. Supply Atw. Donor Profiles On Aid To Water Supply And Sanitation. 2008.

56. WHO U. Progress on Sanitation and Drinking-water, 2010 Update: World Health Organization; 2010.

57. TO A. Health for all beyond 2000: the demise of the Alma-Ata Declaration and primary health care in developing countries. The Medical Journal of Australia. 2003;178(1):17-20.

58. Organization WHO, editor. Ottawa charter for health promotion. First International Health Promotion Conference, Ottawa, Canada, 1986; 1986.

59. Fufa Dugassa B. Ethiopian language policy and health promotion in Oromia. $J$ Soc \& Soc Welfare. 2006;33:69.

60. Cave B, Curtis V. Effectiveness of promotional techniques in environmental health. London School of Hygiene and Tropical Medicine WELL Study Task. 1999; 165.

61. Cragg L. Health promotion theory: McGrawHill Education (UK); 2013.
62. Hubley J, Gilbert C. Eye health promotion and the prevention of blindness in developing countries: critical issues. British journal of ophthalmology. 2006;90(3):279-84.

63. Porter C. Ottawa to Bangkok: changing health promotion discourse. Health Promotion International. 2006;22(1):72-9.

64. Kingdon JW, Thurber JA. Agendas, alternatives, and public policies: Little, Brown Boston; 1984.

65. Crocker J, Saywell D, Shields KF, Kolsky P, Bartram J. The true costs of participatory sanitation: Evidence from community-led total sanitation studies in Ghana and Ethiopia. Science of The Total Environment. 2017;601:1075-83.

66. Robinson A. Total Sanitation: reaching the parts that other approaches can't reach? Waterlines. 2006;25(2):8-10.

67. Terefe B, Welle K. Policy and institutional factors affecting formulation and implementation of sanitation and hygiene strategy. A case study from the Southern Nations Region ('SNNPR') of Ethiopia Addis Ababa: RiPPLE. 2008.

68. Melese M, Alemayehu W, Lakew T, Yi E, House J, Chidambaram JD, et al. Comparison of annual and biannual mass antibiotic administration for elimination of infectious trachoma. Jama. 2008;299(7):778-84.

69. Jamison DT, Breman JG, Measham AR, Alleyne G, Claeson M, Evans DB, et al. Disease control priorities in developing countries. 2006.

70. Supply W, Council SC, UNICEF. Global water supply and sanitation assessment 2000 report: summary of the report. Global water supply and sanitation assessment 2000 report: summary of the report 2000.

71. Cronin AA, Badloe C, Torlesse H, Nandy RK. Water, Sanitation and Hygiene: Moving the Policy Agenda Forward in the Post-2015 Asia. Asia \& the Pacific Policy Studies. 2015;2(2):227-33.

72. Waterkeyn J, Cairncross S. Creating demand for sanitation and hygiene through Community Health Clubs: A cost-effective intervention in two districts in Zimbabwe.

DOI: http://dx.doi.org/10.4314/ejhs.v29i2.15 
Social Science \& Medicine. 2005;61(9):1958-

70.

73. Crocker J, Rowe E. Community-led Total Sanitation in Kenya: Findings from a Situational Assessment. The Water Institute, University of North Carolina, Chapel Hill, http://www.communityledtotalsanitation.org/s ites/communityledtotalsanitation.org/files/Sit uationalAssessment Kenya. pdf [accessed 2 February 2016]; 2015.

DOI: http://dx.doi.org/10.4314/ejhs.v29i2.15 